\title{
FMF revisited
}

European Journal of Human Genetics (2004) 12, 255. doi:10.1038/sj.ejhg.5201170

Published online 11 February 2004

Reply to the Letter from K Konstantopoulos and A Kanta

We thank Konstantopoulos and Kanta ${ }^{1}$ for their useful distinction about Greeks and Greek Orthodoxes, and about Roman-Jews of Greece and Roman-Jews of Rome. Obviously, when we speak about Greeks, we refer to the ancestry and not to the religion. ${ }^{2}$

As regards genetic similarities between Italians and Greeks, we also recall the high prevalence of thalassemia ${ }^{3}$ (many of our FMF patients are microcytemic, too) and the investigation of erythrocyte genetic markers and blood groups between Italians and other European and Near/ Middle Eastern populations. These studies showed that southern and central Italian, Greek and Aegean populations are very homogeneous and quite differentiated from the rest of Europe - including northern Italy - stressing the major impact of the heavy Greek colonization on the genetic pools of the circum-Mediterranean people. ${ }^{4,5}$

Familial Mediterranean fever (FMF) is more and more frequent in Italy: the number of our patients increases exponentially, year after year. At the moment, it has grown by almost $100 \%$ in only 1 year and it is still increasing. After our paper had been accepted for publication by the European Journal of Human Genetics, we also observed one case of phenotype 2 in a family with 3 other members affected by phenotype 1 .

So, the need to look for such patients among those affected by amyloidosis and/or otherwise unexplained renal failure, becomes more urgent.

Since our experience on FMF has emerged from the study of fevers of unknown origin (FUO), we receive patients with these problems from all over Italy. A Research Centre on Periodic Fevers has thus been established in our University.

Finally, to meet the need of a better understanding of FMF population epidemiology and support global projects on genetic diversity, just a few weeks ago we have submitted a proposal to the European Commission for a systematic and considerable integration in FMF research along with the following Euro-Mediterranean institutions (INFLA-NET):

1. Queen Mary and Westfield College, University of London, London, UK

2. Institut de Génétique Humaine, CNRS UPR1142, Montpellier, France

3. Centre Hospitalier Régional et Universitaire de Marseille, Marseille, France

4. Helsinki University Central Hospital, Helsinki, Finland
5. Universitair Medisch Centrum, Utrecht, Netherlands

6. National and Kapodistrian University of Athens, Athens, Greece

7. Rabin Medical Center, Beilinson Campus, Petah Tikva, IL, USA

8. Hadassah University Hospital, Jerusalem, IL, USA

9. The Heller Institute, Sheba Medical Centre, Tel Hashomer, IL, USA

10. Great Ormond Street Hospital for Children, London, UK

11. Hôtel Dieu, Paris, France

12. Hôpital Cochin, Paris, France

13. Hôpital Henri Mondor, Creteil, France

14. Charité Humboldt University, Berlin, Germany

15. University Medical Centre St Raboud, Nijmegen, Netherlands

16. University of Cyprus, Cyprus

17. Facoltà di Farmacia, Università La Sapienza, Roma, Italy

18. National Amyloidosis Centre, Department of Medicine, Royal Free and University College Medical School Royal Free Hospital London, UK

Raffaele Manna, Micaela La Regina, Gabriella Nucera and Giovanni Gasbarrini

Department of Internal Medicine, Catholic University, Largo A. Gemelli, 8, Italy

Isabelle Touitou Laboratoire de Genetique Moleculaire, Hopital A. de Villeneuve, Montpellier, France

Correspondence to: Dr Raffaele Manna, Department of Internal Medicine, Catholic University, Largo A. Gemelli, 8, Italy. Tel: + 39063015 5173; Fax: + 39063550 2775; E-mail: rmanna@rm.unicatt.it

\section{References}

1 Konstantopoulos K, Kanta A: Familial Mediterranean fever seems to be not uncommon in Greece. Eur J Hum Genet 2004; 12(2): 85-86.

2 La Regina M, Nucera G, Diaco M et al: Familial Mediterranean fever is no longer a rare disease in Italy. Eur J Hum Genet 2003; 11: 50-56.

3 Cao A, Rosatelli MC, Monni G, Galanello R: Screening for thalassemia: a model of success. Obstet Gynecol Clin North Am 2002; 29: 305-328.

4 Rickards O, Scano G, Martinez-Labarga C, Taraborelli T, Gruppioni G, De Stefano GF: Genetic history of the population of Puglia (Southern Italy). Gene Geography 1995; 9: 25-40.

5 Rickards O, Martinez-Labarga C, Scano G, Biondi G, Pacaci M, Walter H: Genetic history of the Population of Sicily. Am J Phys Anthropol 1992; 87: 395-406. 